\title{
Reading Difficulties of Primary School English Langauge Learners: A Case Study of District Dera Ghazi Khan
}

\author{
${ }^{a}$ Muhammad Arslan Raheem, ${ }^{\mathrm{b}}$ Madiha Tahir, ${ }^{\mathrm{c}}$ Samee Ullah, ${ }^{\mathrm{d}}$ Muhammad Arshad Javaid \\ ${ }^{a}$ Assistant Professor, University of Education Lahore, Dera Ghazi Khan Campus, Pakistan \\ Email: drarslanraheem@ue.edu.pk \\ ${ }^{\mathrm{b}}$ Lecturer, National University of Modern Languages, Multan, Pakistan \\ Email: Madiha@numl.edu.pk \\ ${ }^{c}$ Lecturer, Bahauddin Zakariya University, Multan, Pakistan \\ Email: sameeullah@bzu.edu.pk \\ d Associate Professor, University of Education Lahore, Dera Ghazi Khan Campus, Pakistan \\ Email: Arshad.javaid@ue.edu.pk
}

\begin{tabular}{l}
\hline ARTICLE DETAILS \\
\hline History: \\
Accepted 15 August 2021 \\
Available Online September 2021 \\
\\
Keywords: \\
EFL Teaching, Reading, Reading \\
Difficulties, Teaching Methods \\
JEL Classification: \\
P32, \\
\hline
\end{tabular}

DOI: $10.47067 /$ real.v4i3.183

\begin{abstract}
The paper aims at investigating reading difficulties that the primary school learners face in English language. Keeping in view the aim of the study, it was further divided into two research objectives: To find out the factors that were causing difficulties in reading English text and To find out the effects that such factors have on the students' performance in reading a text in English. The data was collected using two separate tools for each of the research objectives. Data for the first objective was collected using a semi-structured interview with the English teachers of the mentioned locale of the study. For the second objective nonparticipatory observation was selected as a method to collect data which included a check-list as a tool to mark the effects in the performance of the students with respect to their reading texts in English Language. As far as the analysis of the data is concerned, it was thematically analyzed and the effects were mentioned following the discussion related to the findings of the first research objective. Finally, it was concluded that the students were unable to read the text because of some flaws in the teaching methodology, their lack interest in reading, which was a result of lack of motivation from the parents' as well as teachers' side. The rest of the findings are given in the respective sections.
\end{abstract}

(C) 2021 The authors. Published by SPCRD Global Publishing. This is an open access article under the Creative Commons AttributionNonCommercial 4.0

Corresponding author's email address: sameeullah@bzu.edu.pk

\section{Introduction}

Reading has a number of definitions. It has been defined differently by different authors. Two of the definitions are being discussed here. According to Bhan (2010), reading is a process that, at the same time, involves: reading the lines, reading between the lines and reading beyond the lines. Hence, it implicates that a reader has to be creative and critical while reading a text. In addition to this 
definition, Dadzie (2008) considers reading to be a process through which a reader constructs meaning by interacting the text and its context. Rather than talking more about what reading is; it is need of the study that the reading difficulties and related statistics, highlighted in various studies, must be brought to the reader's focus.

Basic reading difficulties that a lay man faces at basic school, according to Cunningham (200o), are: problem with vocabulary, its recognition and interpretation; reading comprehension and the rate of a pupil's reading. The same findings have been highlighted by Dadzie (2008). There are a number of causes that result in reading difficulties. A general typology of the commonly prevalent reading difficulties has been already given (Ibid). These difficulties are: inappropriate directional habits, limited special comprehension abilities, faulty word identification and recognition, deficient rate of comprehension and difficulty in adapting to the reading needs of content fields. One of the reasons behind such reading difficulties is the lack of being proficient enough to decode message in linguistic form, content and function. Form in this case refers to phonological, syntactic and morphological skills of a language user. The term content in this connection refers to lexical and semantic relationship among various words. In similar terms the item 'function' refers to an individual's ability to use language for pragmatic purposes in the given context. Based on these concepts, a number of reading related problems have been discussed by Deavers (2000). The problems are: letter omission, insertion of extra letters, substitution of similar looking words or sounds and the use of improper inflection during reading.

As a fact, Krashen (2007) put it very clearly that in such a situation where there is a dire need to teach English reading skills to the students at basic level of education, the teachers must do their best to impart the skills to their pupils so that they become able to achieve their academic goals. In the context of Pakistan, most of the focus, in terms of English language, is on the writing and reading skills. And, this seems to be a gateway that a student must get through in order to achieve the desired goals.

As a general observation, similar is the situation when one turns the eye towards public sector schools of the locale of this study. There seems to be a dire need to revise methodology in order to impart knowledge related to English reading skills.

\section{Literature Review}

English reading skill is one of the vital skills whose importance can never be challenged or rejected. As a general observation, students require reading skills in order to marvel at every stage of their academics. Telez (2006) puts it clearly that none can excel till one develops a proficient level in terms of English Language reading. Its significance can be experienced when one looks in to the classrooms and the relevant job markets. In Pakistani context, the students and all the other stakeholders are very concerned about reading skills of students because it is an essential skill that helps them to become competent enough to achieve their academic and professional goals after they are done with their studies. And, according to Tabi (2004), the recent developments which have led to increase in necessity to learn English language for various purposes requires new teaching techniques which are really effective and outcome oriented.

Science and technology have made the world shrink into a global village where it is just a game of seconds rather neon seconds to convey a message to the people sitting at the other side of the worlds. This puts more pressure on the researchers and academicians to never underestimate the importance of English which is a lingua Franca as most of the communication around the world takes place in it- be it academic, scientific or business. Esra (2008) has put it correctly that this can only be achieved when the 
stakeholders focus the basic education levels of students around the world- in this case teaching and learning of English language skills. But, it is quite important to have a look at the other studies that reveal the statistics related to the state of reading in various countries.

As far as developed countries are concerned, particularly the US, The United State Department of Education published a report showing that 2,887,217 children, school going, were receiving services for learning disabilities. Most of them were the children with developmental delays in reading. As per the other studies by June (2005) and Martin (2008) the rate of reading difficulties that prevails in the countries: Britain, New Zealand and the US, ranges $13 \%$ to $17 \%$. Moreover, a large scale national assessment conducted in the US showed that the learners were not maintaining reading skills which they were taught at the basic school level. These statistics were presented by the National Assessment of Educational Progress which was conducted by National Center of Education Statistics in 2010-2011 (Mutenda, 2008). It was suggested that the focus of the educationists must be the early reading skills of a learner.

Similarly, in Netherlands the results of the study that covered the performance of Dutch pupils in an international reading comprehension test in 2011. The study showed that $7 \%$ of the fifteen year old children were unable to perform well enough in the test. That shows that the pupils were unable to function independently in wider society. The average of the Europeans in this regard was near to $17 \%$ (Nalusiba, 2010). In the same research, the New Zealand has been placed on the fourth after the US, Sweden and Finland. In the results, it was mentioned that the most common cause behind such performance of the pupils was the lack of reading culture in the pupils under study (Ibid).

June (2005) has put it in a way that owing to such reading disabilities, the learners are not able to get to the set academic targets. Moreover, getting a complete picture of the leading factors and their effects requires a wide range study of the other countries, which is quite difficult at the given time because most of the literature that has been produced by various countries is in their native languages. This, of course, requires a lot of time, money and energy. But, this does not mean that there is lack of literature with regard to the topic under study.

Dadzie conducted a research in 2008. As per the observations discussed in it, there were certain reading errors which, according to the researchers, were a result of children's instinct. It was defined in a way that children instinctively endeavored to make a sense of what they did while reading any text. Such types of errors were termed as 'miscues' by the researcher and his fellows. Miscues were used as a perspective to explore the underlying processes: psycholinguistic guessing, phonic cueing system. These systems are considered to be subordinates to prediction that a pupil makes based on the cues from syntax and meaning. In broader terms, the process of reading starts inside a reader's mind. Interestingly, a reader prior to reading has certain expectations or perspectives through which the given text is perceived.

There are a number of techniques employed by teachers to teach reading to the children. One of such effective techniques suggested by Antwi (2006) is 'Story method'. Reading is taught to learners in a context of meaning by telling a story. The very first step, in this connection, is to tell students a story which enables the students to become familiar to the context. Their level of familiarity then enables them to read the stories themselves. This increases the chances of their understanding. Another researcher Bashir (2012) suggested that children who are unable to understand the text independently can be helped by letting them read alongside a competent, proficient and systematic adult reader. This is similar to development of language in a child: reading develops with the developmental growth of a 
child. In Chomskian terms, Children are born with a system of acquisition termed as Language Acquisition Device (LAD). This helps them to acquire language. The children in order to be ready to read must do these things: Interpretation of the English language by understanding the given text with relation to mother tongue, reading of the passage loudly and clearly that the listeners are able to comprehend what is being read and retention and reproduction of information which is learnt through reading various texts (Ibid).

\section{Methodology}

It is a qualitative study which covers a number of schools where from the data was collected using two separate tools. The population of study was English language teachers who were teaching at primary level. A sample of ten teachers was selected who were interviewed in order to get data related to the first questionnaire. A great care was taken of ethical considerations. This included the following: getting consent of the participants before the collection of data, they were assured that their identities would be kept confidential and that they were free to withdraw at any point.

After getting consent from the participants, data, related to the second research question, was collected through non-participatory observation in order to check the difficulties that the students faced in reading English in their English classes. The check-list was used as a tool to collect the data. The happenings were marked and were discussed in the results section of the study. It must be noted that 'thematic analysis' was applied in order to extract the data from semi-structured interviews which were collected from the primary school English teachers cum participants of the study.

\section{Findings}

The results of the study have been discussed in this section in details. There were a number of factors, as per the participants which were responsible for the difficulties in English reading of the primary school children at Dera Ghazi Khan.

Firstly, it was highlighted by the participants that the lack of phonological awareness was one of the factors which were responsible for the poor performance of students in terms of their reading in English language. By phonological awareness, they meant the mental representation of the English phonemes in the metal linguistic inventory of the students. Owing to the lack of input in English language, the students were unable to build an accurate phonological representation of English phonemes. Therefore, they were having problems like mispronunciation while reading various texts in English language. That can be simply defined in a way that students were not able to decode alphabetical representation of the lexical items due to the lack of phonological representation. And, this was not generalized as there were some students who could read the texts accurately and fluently.

It was quite surprising that the participants accepted that they were unaware of the modern teaching methods in terms of reading. Upon asking regarding 'story method' in terms of teaching reading, some of the participants replied that they were completely unaware and they wondered what it could be. Even during the classroom observations, it was found that the students, as a reading task, were just coming out, standing along rostrum and reading the texts loudly and when they were done with English reading, they were just translating them in English language as they were taught by their teachers. There seemed to be a gap in terms of their understanding of what was being communicated to them in the text.

Moreover, it was found that environment was one of the factors that impacted reading of the students. According to the participants, their students could be divided into two groups: those who 
were encouraged to read at home and those who lacked motivation or inclination towards reading. The former were found to be very fluent readers and their writing reflected the level of their understanding of the text. The participants even commented that such students were even independent in terms of guidance in classes. They even read the uncovered texts by themselves and were able to make a sense out of it. The latter, according to the participants, were unable to do so because they lacked motivation. They were not having environment that could encourage them to start reading by themselves.

Additionally, there were the factors: L1 interference, lack of motivation, lack of text books and reading materials, parental literacy level, poverty, innutritious food, lack of proper furniture for study, which were responsible for the poor performance of students in terms of their low level proficiency in English reading skills. Primary level students were facing problems in terms of decoding, fluency, accuracy, pronunciation and vocabulary while reading the assigned texts. When a student does not have oral input of a term; the student will not be able to decode that particular vocabulary item when it is presented to him/her in the form of text. Therefore, it is very vital that the students must be provided, at first, the oral input of the vocabulary so that they become able to read it in the form of a text.

The students that show such sort of difficulties in terms of their reading skills suffer a lot in their academic growth as already discussed in the literature review section of the study. To sum up, their difficulties can be describes in terms of decoding and reading out a multisyllabic word: that is their inability to process the words phonologically. Therefore, the students must be given the input related to linguistic mechanism that words are made up of syllables which are a combination of various meaningful speech patterns.

\section{Conclusion}

It was found through this study that most of the students were facing a number of difficulties in terms of their English reading skills. These difficulties were related to decoding of lexical items, mispronunciation of words, identifying and reading a multisyllabic word etc. As far as the factors behind these difficulties are concerned, they were: the lack of motivation, lack of phonological awareness, lack of environment, inadequate reading related teaching methodologies and most importantly rote learning.

\section{References}

Bach, S., Richardson, U., Brandeis, D., Martin, E., \& Brem, S. (2013). Print-specific multimodal brain activation in kindergarten improves prediction of reading skills in second grade. Neuroimage, 82, 605-615.

Can, C., Ewert, A., Gabrys-Barker, D., Kassotaki, I., Kilimci, A., \& Król-Markefka, A. Esra Altunkol is a reader and PhD candidate at the ELT Department of Cukurova University, Turkey. Her research interests include adult SLA from the generative perspective and ELT methodology. Marcus Callies is an assistant professor in English Linguistics at the University of Marburg, Germany. His research interests are second.

Çelik, S., \& Kasapoglu, H. (2014). Implementing the recent curricular changes to English language instruction in Turkey: Opinions and concerns of elementary school administrators. South African Journal of Education, 34(2).

Cunningham, J. W., Many, J. E., Carver, R. P., Gunderson, L., \& Mosenthal, P. B. (200o). How will literacy be defined in the new millennium?. Reading research quarterly, 35(1), 64-71.

Dadzie, P. S. (2008). Reading for education: The role of libraries.

Deavers, R., Solity, J., \& Kerfoot, S. (2000). The effect of instruction on early nonword reading 
strategies. Journal of Research in Reading, 23(3), 267-286.

Freeman, Y. S., Freeman, D. E., \& Mercuri, S. (2005). Dual language essentials for teachers and administrators (pp. 1-50). Portsmouth, NH: Heinemann.

Hamann, E. T., \& Reeves, J. (2013). Interrupting the professional schism that allows less successful educational practices with ELLs to persist. Theory Into Practice, 52(2), 81-88.

Krashen, S., \& Brown, C. L. (2007). What is academic language proficiency. STETS Language \& Communication Review, 6(1), 1-5.

Li, F. (2010). A study of English reading strategies used by senior middle school students. Asian Social Science, 6(10), 184 .

Mutenda, J. (2008). Teaching reading in grade 4 Namibian classrooms: A case study (Doctoral dissertation, Rhodes University).

Nalusiba, P. (2010). Strategies for the development of a reading culture in Uganda primary schools: Case studies of four selected Universal Primary Education schools in Kampala district. Master's degree dissertation, Makerere University, Uganda.

Orgun, F. (2004). Effects of guided reading on upper-intermediate level English language learners' writing outcome at the Turkish Prime Minister (Master's thesis).

Owusu-Acheaw, M., \& Larson, A. G. (2014). Reading habits among students and its effect on academic performance: A study of students of Koforidua Polytechnic. Library philosophy and practice, o_1.

Paksoy, E. (2008). The effects of process drama on enhancement of self-esteem and oral skills in English language classroom. Unpublished master's thesis). Cukurova University, Adana, Turkey. 